\section{Post-colonoscopy tension pneumothorax resulting from colonic barotrauma in a previously unrecognised left-sided diaphragmatic hernia}

When unexpected diaphragmatic hernias result in colonic perforation during colonoscopy, they are always associated with pneumothorax and are always fatal $[1,2]$. We report a case of colonoscopy-induced tension pneumothorax due to an undiagnosed diaphragmatic hernia without colonic perforation.

A 46-year-old man with no history of thoracoabdominal trauma underwent colonoscopy for rectal bleeding. Colonoscopic progress though initially straightforward became difficult beyond the splenic flexure. The procedure was abandoned due to abdominal discomfort. The patient was discharged after a satisfactory post-procedural examination. After 6 hours he presented with chest pain and breathlessness due to a left-sided tension pneumothorax ( $\bullet$ Fig. 1). Following decompression and chest drain insertion, he was managed in the intensive therapy unit. The left lung failed to re-expand due to a left-sided diaphragmatic hernia ( $\bullet$ Fig. 2) that was later repaired by open surgery. The hernia contained an incarcerated colonic loop that was resected with primary colonic anastomosis followed by closure of the hernial defect. Histological examination of the specimen (๑ Fig. 3) suggested ischemic damage but not perforation. The lung re-expanded after 4 days and the patient was discharged shortly afterwards. Radiological evidence suggested the hernia was probably of traumatic origin.

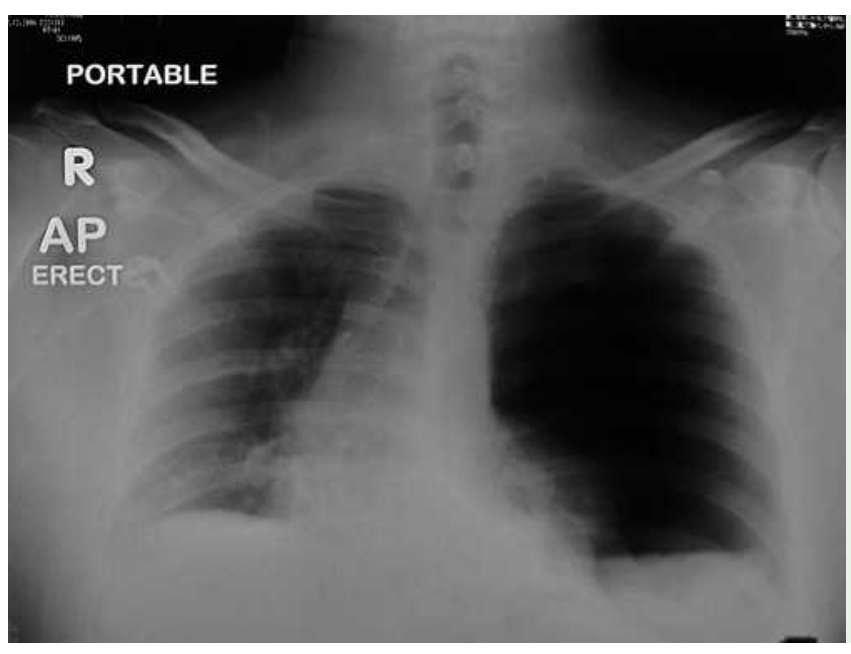

Fig. 1 Portable erect chest X-ray taken on emergency admission of patient with tension pneumothorax. There is a left-sided tension pneumothorax, with absence of air under the diaphragm.

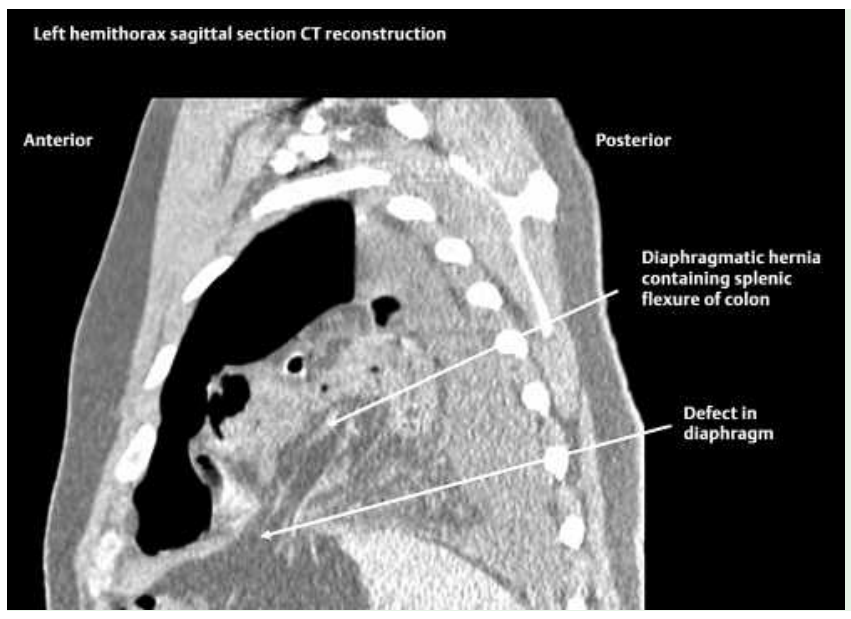

Fig. 2 Thoracic computed tomography (CT) scan was indicated because of the failure of the left lung to re-expand some days after the insertion of a chest drain. There is a defect in the left hemidiaphragm, allowing the herniation of colon into the left hemithorax.
Late diagnosis of traumatic hernias impedes their management, with unexpected diagnoses after a latency period $[3,4]$ or at post-mortem [5]. The abdomen-tothorax pressure gradient favors progressive herniation of viscera through undiagnosed diaphragmatic defects. The lack of supporting evidence (radiological or histological) and the nonfatal outcome meant that it was unlikely colonic perforation had occurred. The hernia contained a colonic loop, causing acute angulation and impeding the passage of the colonoscope. We are convinced that the pneumothorax resulted from the avulsion of adherent lung away from the incarcerated colonic segment ( $\bullet$ Fig. 4). Maneuvering of the instrument and stretching of the colonic segment on air-insufflation caused avulsion of adherent colon, creating a defect in the apposed lung surface along with rupture of associated alveoli. Good postprocedural advice, excellent emergency medical management and sound surgical repair ensured that the patient had a good outcome.

Endoscopy_UCTN_Code_CPL_1AJ_2AC

E. Alabraba ${ }^{1}$, D. Gourevitch ${ }^{2}$,

R. Hejmadi ${ }^{3}$, T. Ismail ${ }^{1}$, R. Cockel ${ }^{1}$

Endoscopy Unit, UHB NHS Trust, Birmingham, UK

2 Department of Surgery, UHB NHS Trust, Birmingham, UK

3 Pathology Department, UHB NHS Trust, Birmingham, UK

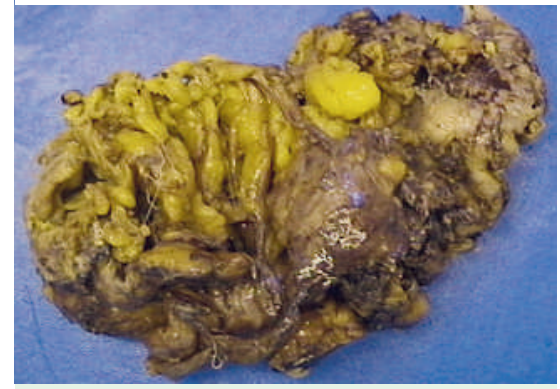

Fig. 3 Gross appearance of the colonic resection specimen. The incarcerated colonic segment had gross necrosis of fat on its serosal surface. There was no obvious site of perforation and no fibrinous exudates to suggest a site of perforation. 


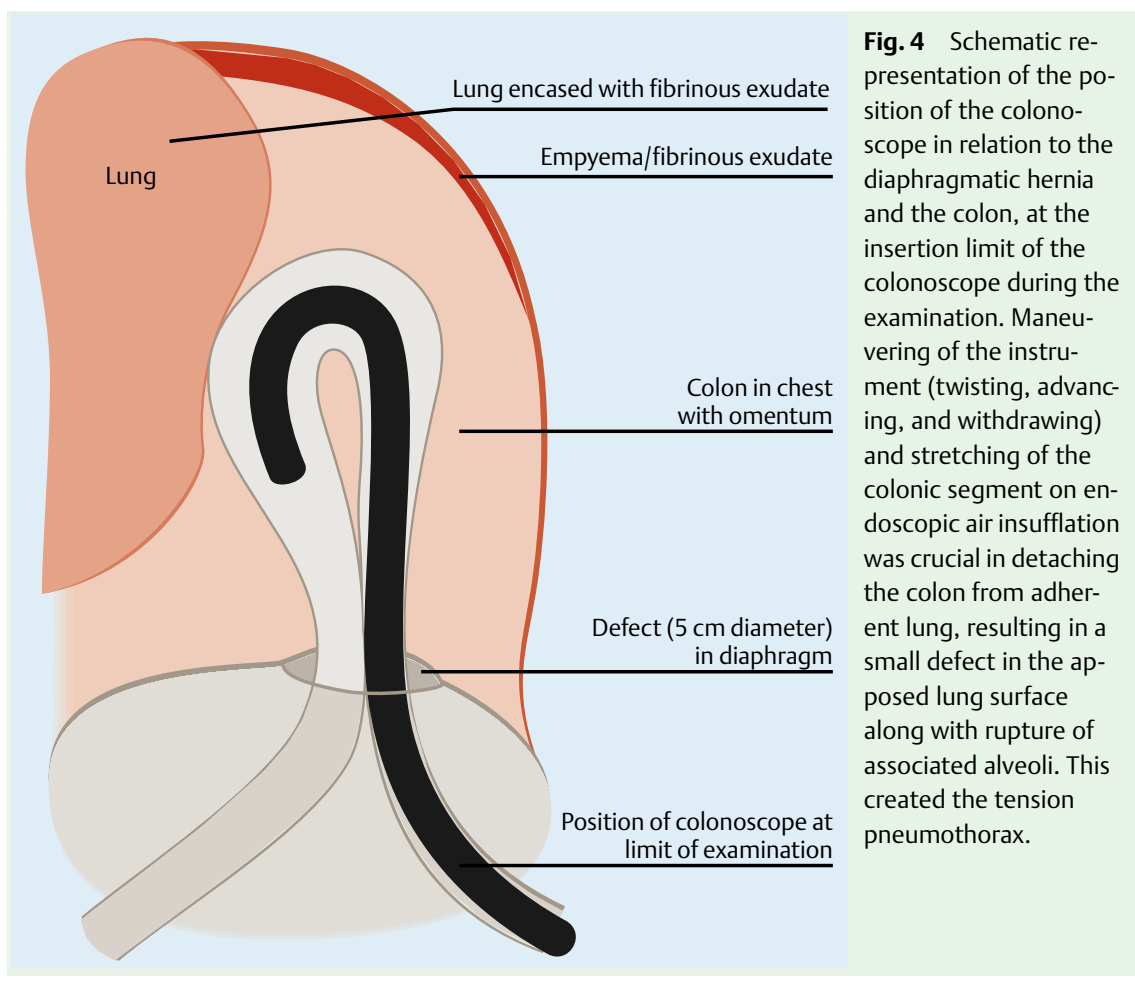

\section{References}

1 Chae HS, Kim SS, Han SW et al. Herniation of the large bowel through a posttraumatic diaphragmatic defect during colonoscopy: report of a case. Dis Colon Rectum 2002; 45: $1261-1262$

2 Baumann UA, Mettler M. Diagnosis and hazards of unexpected diaphragmatic hernias during colonoscopy: report of two cases. Endoscopy 1999; 31: 274-276

3 Ahmad J, Beattie GC, Kennedy R et al. Penetrating trauma to the junctional zone needs aggressive management. BMJ 2007; 334: $257-258$
4 Ball T, McCrory R, Smith JO, Clements JL Jr. Traumatic diaphragmatic hernia: errors in diagnosis. AJR Am J Roentgenol 1982; 138: 633-637

5 Christophi C. Diagnosis of traumatic diaphragmatic hernia: analysis of 63 cases. World J Surg 1983; 7: 277-280

\section{Bibliography}

DOI 10.1055/s-2008-1077366

Endoscopy 2008; 40: E128-E129

(c) Georg Thieme Verlag KG Stuttgart · New York . ISSN 0013-726X

\section{Corresponding author}

\section{E. B. Alabraba, MD}

Liver Research Group

Medical School, University of Birmingham Birmingham B15 2TT

UK

Fax: + 44-121-41-58701

e.b.alabraba@bham.ac.uk 